\title{
Bitlis İlinde Farklı Yakıtlar ve Duvar Bileşenleri İçin Optimum Yalıtım Kalınlığı ve Enerji Tasarrufunun Analizi
}

\author{
Bahadır Erman YÜCE ${ }^{1,2 *}$, Mahmut Caner ACAR ${ }^{3}$ \\ ${ }^{1}$ Bitlis Eren Üniversitesi, Mühendislik Mimarlık Fakültesi, Makine Mühendisliği Bölümü, Bitlis, Türkiye \\ ${ }^{2}$ Technical University of Denmark, Department of Civil Engineering, International Centre for Indoor \\ Environment and Energy, Denmark \\ ${ }^{3}$ Niğde Ömer Halisdemir Üniversitesi, Mühendislik Fakültesi, Makine Mühendisliği Bölümü, Niğde, Türkiye \\ (ORCID: 0000-0002-2432-964X) (ORCID: 0000-0002-6206-5374)
}

\begin{abstract}
$\ddot{O} z$
Küresel olarak enerji talebi sürekli olarak artmaktadır ve bu durum hane başına olan enerji tüketimini arttırmaktadır. Bu çalışmada Bitlis ilinde optimum yalıtım kalınlığı değeri ve bu değere bağlı olarak hesaplanan enerji tasarrufu, yıllık enerji kazancı ve geri ödeme süresi kullanılan farklı yakıtlar, farklı yalıtım malzemeleri ve farklı duvar bileşenleri için incelenmiştir. Bitlis, Türkiye'nin en ağır kış şartlarını yaşayan illerinden biri olması sebebiyle elde edilen sonuçlar önem arz etmektedir. Çalışmada, yakıt için kömür ve doğalgaz, yalıtım malzemesi için taş yünü, cam yünü, EPS ve XPS ve duvar bileşeni için ise yatay delikli tuğla ve Bitlis pomzasından elde edilmiş bims kullanılmıştır. Elde edilen sonuçlar duvar malzemesi olarak yatay delikli tuğla yerine bims kullanımı ile optimum yalıtım kalınlığında kayda değer bir azalmanın olduğunu göstermiştir. Çalışmada elde edilen sonuçlara göre optimum yalıtım kalınlığının 0,027-0,096 m aralığında, enerji tasarrufunun 34,636-69,525 TL/m² aralığında, yıllık enerji kazancının \%26,626-\%62,69 aralığında ve geri ödeme süresinin ise 1,595-3,756 yıl değerleri aralığında değiştiği görülmüştür.
\end{abstract}

Anahtar kelimeler: Optimum yalıtım kalınlı̆̆

\section{Analysis of Optimum Insulation Thickness and Energy Saving for Different Fuels and Wall Components in Bitlis Province}

\begin{abstract}
Globally, the demand for energy is constantly increasing, and as a result, it increases energy consumption per household. In the present study, the value of optimum insulation thickness and the energy savings calculated based on this value, payback period and annual energy gain were examined in terms of various fuels, insulation materials and wall components in Bitlis province. Bitlis is one of the provinces with the harshest winter conditions in Turkey so the results obtained are important. In the study, natural gas and coal were chosen for fuel, EPS, XPS, rock wool and glass wool were chosen for insulation material and horizontally perforated brick and pumice block obtained from Bitlis pumice mines were chosen for wall components. Results showed that when using pumice block obtained from Bitlis pumice, the optimum insulation thickness for all cases is lower than the use of bed-hole bricks. According to the results, there was a significant decrease in the optimum insulation thickness with the use of pumice instead of horizontal perforated brick as wall material. Results also show that the optimum insulation thicknesses differ between 0,027-0,096 m, energy savings between 34,636-69,525 TL/m², annual energy gain between $26,626 \%-62,69 \%$, and the payback period between $1,595-3,756$ years.
\end{abstract}

Keywords: Optimum insulation thickness, Bitlis pumice, Energy saving.

\section{Giriş}

Enerjinin verimli kullanılması günümüzde ülkelerin enerji politikaları için en önemli unsurlarından biri haline gelmiştir. Birleşmiş Milletler çevre programı verilerine göre binalar küresel enerjinin \% 40'ını

\footnotetext{
*Sorumlu yazar: beyuce@beu.edu.tr

Geliş Tarihi: 30.06 .2021 , Kabul Tarihi: 27.09.2021
} 
kullanmaktadır [1]. Binalarda enerji tüketimi en yüksek uygulamalardan biri ise 1sitma ve soğutma sistemleridir. Bu sistemlerin en verimli şekilde kullanılabilmesi için binaların 1sıl olarak iyi bir şekilde yalıtılması gerekmektedir. İyi yalıtılmış binalar hem dolaylı hem de doğrudan çevre kirliliğini azaltır ve ülke ekonomisine olumlu katkı sağlar. Yalıtım 1sıl konfor sıcaklıklarına ulaşılmasının daha az maliyetli hale gelmesini sağlar. $\mathrm{Bu}$ durum iyi yalıtılmış binalarda çalışan üretkenliğinin de artacağını göstermektedir.

Yalıtımlı binalarda, yapı elemanları ile dış ortam arasındaki 1sı transferi azalır. Bu durum soğuk havalarda iç ortamdan dış ortama olan ısı kaybını azaltırken sıcak havalarda ise dış ortamdan iç ortama 1S1 geçişini azaltır.

İzolasyon malzemesinin kalınlığının arttırılması 1sı transferini azaltır fakat bu durum aynı zamanda izolasyon maliyetini de arttırır. Bu nedenle "optimum" değere ulaşmak çok önemlidir. Optimum yalıtım kalınlığ 1 , yalıtım ve kaybedilen 1sı maliyetleri toplamının minimum olduğu kalınlık değeridir.

Optimum yalıtım kalınlığı ile ilgili akademik literatürde yapılmış birçok çalışma bulunmaktadır. Gölcü ve ark. yaptıkları çalı̧̧mada Denizli ili için optimum yalıtım kalınlı̆̆ı, enerji tasarrufu ve geri ödeme süresi değerlerini ithal fuel oil ve kömür için hesaplamışlardır [2]. Dış cephe yalıtım malzemesi olarak taş yünü, yakıt olarak ise ithal kömür kullandıklarında, yıllık tasarrufu $\% 42$, optimum yalıtım kalınlığını 0,048 m, ve geri ödeme süresini ise 2,4 yıl olarak bulduklarını ifade etmişlerdir. Özel yaptığı çalışmada optimum yalıtım kalınlığını dinamik şartlar altında hesaplamıştır [3]. Impilicit sonlu farklar metodunu kullanarak yıllık ısıtma yükünü kararlı periyodik şartlar kullanarak hesaplamıştır. Çalışmasında yakıt olarak, doğal gaz, fuel-oil ve ithal kömür ve yalıtım malzemesi olarak XPS kullanılmıştır. Elazığ ili için optimum yalıtım kalınlığı 0,040 m olarak doğal gaz yakıtı kullanıldığı durumda elde edilmiştir. Kaynaklı, yaptığı çalışmada, optimum yalıtım kalınlığının hesaplanmasında kullanılan parametrelerin etkilerini incelemiştir [4]. Isıtma ve soğutma yüklerinin, binanın ömrünün, enflasyon oranının, enerji maliyetlerinin ve yalıtım malzemesinin 1sı iletim katsayısı değerinin artması ile optimum yalıtım kalınlığının da arttığını ifade etmiştir. Faiz oranı, yalıtım malzemesinin maliyeti, toplam duvar ısıl direnci ve performans katsayısı (COP) değerlerinin artması ile ise azaldığını göstermiş̧tir. Işık ve Tuğan, optimum yalıtım kalınlığını Kars, Hakkari ve Tunceli illeri için araştırmışlardır [5]. Çalışmalarında, yalıtım malzemesinin 1sıl iletkenlik katsayısı, duvar kalınlığı, derece-gün sayısı ve yakıt tipine göre maliyet eğrilerini oluşturmuş ve geri ödeme sürelerini hesaplamışlardır. Hakkari için $8,2 \mathrm{~cm}$, Tunceli ili için $7,9 \mathrm{~cm}$ ve Kars için optimum yalıtım kalınlığı $10,4 \mathrm{~cm}$ olarak hesaplandığını ifade etmişlerdir. Özel ve Tunç, ise yaptıkları çalışmada Kars ili için optimum yalıtım kalınlığını 1şınım özelliklerini de dikkate alarak bina dış duvarları için hesaplamışlardır [6]. Kars ili için, 3897 ve 4867 DG değerlerine göre optimum yalıtım kalınlıklarının sırasıyla 8 ve $9 \mathrm{~cm}$ olarak elde edildiğini belirtmişlerdir. Uçar ve Dumrul ise yaptıkları çalışmada dış taraftan yalıtımlı duvar ve sandviç duvar için hesaplama yapmışlardır [7]. Yakıt için kömür ve doğalgaz kullanmışlardır. Sıkıştırılmış polistiren (XPS) ve genleştirilmiş polistiren (EPS) ise yalıtım malzemesi olarak yaptıkları çalışmada kullanılmıştır. Çalışmalarının sonucunda hem soğutma ve hem de ssıtma durumu için enerji tasarrufları $24,79 \mathrm{TL} / \mathrm{m}^{2}$ ile $60,45 \mathrm{TL} / \mathrm{m}^{2}$ arasında, geri ödeme süreleri 2,5714 ve 4,2062 yıl arasında ve optimum yalıtım kalınlıklarının ise $0,0549 \mathrm{~m}$ ile $0,0836 \mathrm{~m}$ arasında değiştiğini ifade etmişlerdir. Bademlioğlu ve ark. İse Bitlis için optimum yalıtım kanlığını yoğuşma durumunu dikkate alarak şubat ayı için hesaplamışlar ve yalıtım kalınlığının en az 0,104 m olması gerektiğini ifade etmişlerdir [8]. Canbolat ve ark. yaptıkları çalışmada [9] optimum yalıtım kalınlığına etki eden parametrelerin etki oranlarını incelemiş ve en etkili parametrenin \%27,33 ile 1sıtma gün sayısı olduğunu, en az etkili parametrenin ise \%3,21 ile ssıtma sisteminin verimi olduğunu belirtmişlerdir. Canbolat ve ark. [10] yaptıkları bir başka çalışmada ise İstanbul ili için optimum yalıtım kalınlığını güneş radyasyonunu da dikkate alarak 0,047 m olarak hesaplamışlardır. Kürekçi [11] ise Türkiye'de bulunan 81 ilin farklı yakıtlar ve 1sıtma senaryoları için tasarruf miktarını, optimum yalıtım kalınlığını ve geri ödeme süresini hesaplamıştır. Huang ve ark. ise [12] yalıtım malzemesi olarak aerogel kullanmıştır. Aerogeli yaygın kullanılan diğer yalıtım malzemeleri ile kıyasladıklarında $0,0037 \mathrm{~m}$ ile en düşük optimum yalıtım değerine sahip olduğunu ifade etmişlerdir.

$\mathrm{Bu}$ çalışmada ise diğer çalışmalardan farklı olarak güncel ekonomik verilerle Bitlis ili özelinde yalıtım malzemesi olarak taş yünü, cam yünü, EPS ve XPS, yakıt olarak kömür ve doğalgaz, yapı 
elemanı olarak yatay delikli tuğla ve Bitlis pomzasından elde edilmiş bims kullanımı durumunda enerji tasarrufu, optimum yalıtım kalınlığı, geri ödeme süresi ve yıllık enerji kazancı değerleri hesaplanmıştır.

\section{Materyal ve Metot}

Binalarda meydana gelen 1sı kayıpları en fazla bina dış cephe duvarlarında meydana gelmektedir. Binalardaki dış cephe duvarlarında kullanılan duvar modellerinden biri Şekil 1'de gösterilmiştir.

Tablo 1. Yalıtım malzemelerinin ve duvar bileşenlerinin özellikleri. [7] [13]

\begin{tabular}{|l|l|l|l|}
\hline & $\begin{array}{l}\text { Kalınlık } \\
(\mathbf{m})\end{array}$ & Isı iletim katsayısı k (W/mK ) & $\begin{array}{l}\text { Isıl direnç R } \\
\left(\mathbf{m}^{2} \mathbf{K} / \mathbf{W}\right)\end{array}$ \\
\hline İç sıva & 0,02 & 0,87 & 0,0229 \\
\hline Yatay Delikli Tuğla & 0,13 & 0,45 & 0,2888 \\
\hline Bims (Bitlis Pomzası) & 0,1 & 0,18 & 0,5555 \\
\hline Dış sıva & 0,02 & 1,4 & 0,0142 \\
\hline $\mathrm{R}_{\mathrm{i}}$ & - & - & 0,1667 \\
\hline $\mathrm{R}_{\mathrm{o}}$ & - & - & 0,0454 \\
\hline Taş yünü & - & 0,04 & - \\
\hline XPS & - & 0,032 & - \\
\hline EPS & - & 0,033 & - \\
\hline Cam yünü & - & 0,045 & - \\
\hline Toplam (Tuğla için) & & & 0,53 \\
\hline Toplam (Bims için) & & & 0,80 \\
\hline
\end{tabular}

Duvar bileşenlerinin özellikleri Tablo 1'de gösterilmiştir. Bitlis pomzasının 1sıl özellikleri için TSE 1745 ve literatürden [4] faydalanılmıştır.

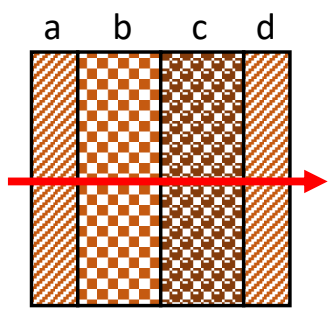

Şekil 1. Duvar modeli bileşenleri a) iç sıva, b) yatay delikli tuğla, c) yalıtım levhası, d) dış sıva

Dış duvarlardan 1sı kaybını etkileyen temel faktörler duvarın toplam 1sıl direnci ve 1sı iletim özelliğidir. Duvar ısı iletim direncinin artması ve ısı iletim katsayısının azalması dış duvardan dış ortama geçecek ısıyı azaltmaktadır. Bina dış duvarından olan 1sı kaybı aşağıdaki eşitlikle ifade edilebilir:

$q=U \cdot \Delta T$

Eşitlik 1'de ifade edilen U toplam 1sı transfer katsayısıdır ve aşağıdaki Eşitlik ile hesaplanır: 


$$
U=\frac{1}{R_{\text {iç }}+R_{\text {duvar }}+R_{\text {yalıtım }}+R_{\text {dls }}}
$$

Eşitlik 2'de gösterilen $R_{i c ̧}$ ve $R_{d l s ̧}$ sırası ile iç ve dış yüzeylerin ısıl dirençleridir. $R_{\text {duvar }}$ ise yalıtımsız duvar tabakasının 1sıl direncini ifade etmektedir. Yalıtım malzemesinin 1s1l direnci de $R_{\text {yalıtım }}$ ile gösterilmiştir ve Eşitlik 3 ile ifade edilir:

$$
R_{\text {yalıtım }}=\frac{x}{k}
$$

Burada k ve x sırası ile 1sı iletim katsayısı ve yalıtım malzemesinin kalınlığıdır. Yalıtımsız duvarın toplam isıl direnci ise $R_{\text {duvar, } t}$ ile ifade edilir ve bu çalışmada $0,84 \mathrm{~m}^{2} \mathrm{~K} / \mathrm{W}$ olarak kabul edilmiştir. $R_{\text {duvar }, t}$ Eşitlik 4 'te gösterilmiştir.

$$
R_{\text {duvar }, t}=R_{i c ̧}+R_{\text {duvar }}+R_{d l s ̧}
$$

Toplam 1sı transfer katsayısı ise yukarıda elde edilen ısıl direnç ifadeleri cinsinden aşağıda gösterilmiştir:

$$
U=\frac{1}{R_{\text {duvar }, \mathrm{t}}+R_{\text {yalltum }}}
$$

Birim yüzeyde meydana gelen y1llık 1sı kaybı Eşitlik 6'da gösterilmiştir:

$$
q=86400 \cdot D G \cdot U
$$

Burada ifade edilen DG değeri Isıtma Derece Gün sayısını (Heating Degree Day-HDD) ifade etmektedir. Bu çalışmada Bitlis için DG değeri 3545'tir. Eşitlik 7'de yıllık enerji ihtiyacı hesabı gösterilmiştir:

$$
E_{A}=\frac{86400 \cdot D G \cdot U}{\eta}
$$

Bu eşitlikteki $\eta$ ifadesi yanma verimidir. Yukarıdaki eşitlikte toplam ısıl direnç ifadesi açılırsa,

$$
E_{A}=\frac{86400 \cdot D G}{\left(R_{\text {duvar }, t}+R_{\text {yalutum }}\right) \cdot \eta}
$$

ve Eşitlik 3 aşağıdaki gibi eşitliğe eklenirse:

$$
E_{A}=\frac{86400 \cdot D G}{\left(R_{\text {duvar }, t}+\frac{x}{k}\right) \cdot \eta}
$$

Eşitliği elde edilir. Isıtma için gerekli enerji ihtiyacı belirlendikten sonra yakıt tüketimi bulunabilir. Enerji ihtiyacına karşılık gelen yakıt tüketimi Eşitlik 10 ile bulunabilir: 


$$
m_{f A}=\frac{86400 \cdot D G}{\left(R_{\text {duvar }, t}+\frac{x}{k}\right) \cdot H_{u} \cdot \eta}
$$

Yukarıdaki eşitlikte yer alan $H_{u}$ ifadesi kullanılan yakıtın alt 1sıl değerini ifade eder. Bu çalışmada yakıt olarak doğalgaz ve kömür kullanılmıştır. Kullanılan yakıtların özellikleri Tablo 2'de ifade edilmiştir.

Tablo 2. Kullanılan yakıtlar ve özellikleri

\begin{tabular}{|l|l|l|l|}
\hline Yakıt & $\begin{array}{l}\text { Alt Isl Değer } \\
\left(\boldsymbol{H}_{\boldsymbol{u}}\right)\end{array}$ & $\begin{array}{l}\text { Yakıt birim fiyatı } \\
\left(\boldsymbol{C}_{\boldsymbol{f}}\right)\end{array}$ & $\begin{array}{c}\text { Yakma sistemi verimi } \\
\boldsymbol{\eta}\end{array}$ \\
\hline Kömür & $29380000 \mathrm{~J} / \mathrm{kg}$ & 0,68 & 0,65 \\
\hline Doğalgaz & $34541000 \mathrm{~J} / \mathrm{m}^{3}$ & 1,515 & 0,93 \\
\hline
\end{tabular}

Enerji maliyetinin birim alan başına gösterimi ise Eşitlik 11'de gösterilmiştir:

$$
C_{A}=\frac{86400 \cdot D G \cdot C_{f}}{\left(R_{\text {duvar }, t}+\frac{x}{k}\right) \cdot H_{u} \cdot \eta}=m_{f A} \cdot C_{f}
$$

Yukarıda ifadede geçen $C_{f}$ terimi yakıtın birim fiyatıdır. Tablo 2'de tüm yakıtların birim fiyatları gösterilmiştir. Yıllık enerji maliyeti aynı zamanda optimum yalıtım kalınlığını hesaplamak için gereklidir.

$$
P W F=\frac{(1+r)^{N}-1}{r \cdot(1+r)^{N}}=m_{f A} \cdot C_{f}
$$

Eşitlik 11 ve 12'de şimdiki değer faktörü (present worth factor - PWF) gösterilmiştir [14]. N y1llık bir ömür boyunca toplam 1sitma maliyeti, PWF kullanılarak güncel para değeri cinsinden hesaplanabilir. Eşitlik 11 'de geçen $r$ terimi bu çalışma için enflasyon oranını $g$ ve faiz oranı $i$ ile Eşitlik 13'de gösterildiği gibi hesaplanır:

$$
r=\frac{i-g}{1+g}
$$

Eğer; $i>g$ ise $r=(i-g) /(1+g), i<g$ ise $r=(g-i) /(1+i)$ olarak hesaplanır. Bu çalışmada $i=0,17, g=0,16$ olarak kabul edilerek hesaplamalar yapılmıştır. Bina yalıtım maliyeti $\mathrm{TL} / \mathrm{m}^{2}$ cinsinden aşağıdaki gibi hesaplanır:

$$
C_{\text {yalttim }}=C_{i} \cdot x
$$

Eşitlik 14 'te yer alan $C_{i}$ ifadesi $\mathrm{TL} / \mathrm{m}^{3}$ cinsinden yalıtım malzemesinin fiyatıdır. Çalışmada yalıtım malzemelerinin $C_{i}$ değerleri taş yünü için $680,903 \mathrm{TL} / \mathrm{m}^{3}$, XPS için $1190,276 \mathrm{TL} / \mathrm{m}^{3}$, cam yünü için $458,333 \mathrm{TL} / \mathrm{m}^{3}$ ve EPS için ise $1038,2 \mathrm{TL} / \mathrm{m}^{3}$ 'dür.

Yalıtım yapılmış bir binanın toplam ısıtma maliyeti; şimdiki değer faktörü ve yalıtım maliyeti de dikkate alınarak aşağıdaki gibi hesaplanır: 
$C_{t, \text { yalltim }}=C_{A} \cdot P W F+C_{i} \cdot x$

Eşitlik 11 ve Eşitlik 14, Eşitlik 15 'te yerine yazılırsa yalıtım yapılmış bir binanın toplam 1sıtma maliyeti Eşitlik 16'da ifade edildiği gibi hesaplanabilir:

$$
C_{t, \text { yalttim }}=\frac{86400 \cdot D G \cdot C_{f} \cdot P W F}{\left(R_{\text {duvar }, t}+\frac{x}{k}\right) \cdot H_{u} \cdot \eta}+C_{i} \cdot x
$$

Eşitlik 15 'te ifade edilen yalıtım yapılmış bir binanın toplam ısıtma maliyetini en aza indiren yalıtım kalınlığı optimum yalıtım kalınlığıdır. $C_{t, y a l ı t ı m}$ 'ın $x$ 'e göre türevi alınır ve sıfıra eşitlenirse optimum yalıtım kalınlığı $x_{\text {opt }}$ elde edilir:

$$
x_{\text {opt }}=293.94\left(\frac{D G \cdot C_{f} \cdot P W F \cdot k}{H_{u} \cdot C_{i} \cdot \eta}\right)-k \cdot R_{d u v a r, t}
$$

\section{Bulgular ve Tartışma}

Küresel enerji ihtiyacı artan talebin ve ihtiyaçların sonucu olarak sürekli olarak artmaktadır. Bu sebeple enerjinin verimli kullanılması ve enerji tasarrufu gibi konular önemini arttırmıştır. Bu çalışmada dış cephe duvarı yalıtılmış bir bina için optimum yalıtım kalınlığı, enerji tasarrufu, yıllık enerji kazancı ve geri ödeme süresi farklı yakıt türleri, duvar bileşenleri ve yalıtım malzemeleri için MS Excel yazılımı ile hesaplanmıştır. Ayrıca bina duvarında kullanılan bims için Bitlis pomzasının özellikleri kullanılarak hesaplar yapılmıştır. Taş yünü için yapılan hesaplamalar sonucunda elde edilen değerler Tablo 3 'te verilmiştir. Hem bims hem de yatay delikli tuğla için kömür kullanımında yalıtım kalınlığının daha düşük olduğu görülmüştür. Doğalgazın birim fiyatı daha yüksek olduğundan yalıtım yapılması durumunda enerji tasarrufu ve yıllık enerji kazancının beklenildiği üzere daha fazla olduğu görülmüştür. Yatay delikli tuğla kullanımı için geri ödeme süreleri kömür ve doğalgaz için sırasıyla 1,905 ve 1,728 yıl olarak hesaplanmıştır. Yapı elemanı olarak bims kullanılması durumunda ise, pomzanın 1sı iletim katsayının düşük olması sebebiyle yalıtım kanlığı azalmıştır. Duvar bileşeni malzemesinin 1sıl iletkenliğinin düşük olması yalıtım malzemesine olan ihtiyacı azaltmıştır. Geri ödeme süreleri de bu bağlamda kömür için 2,9 yıla, doğalgaz için 2,4 yıla çıkmıştır.

Tablo 3. Taş yünü için farklı yakıt türlerinde enerji tasarrufu, optimum yalıtım kalınlığı, geri ödeme süresi ve

\begin{tabular}{|c|c|c|c|c|c|c|c|c|}
\hline \multirow{2}{*}{$\begin{array}{c}\text { Yalıtım } \\
\text { malzemesi }\end{array}$} & \multicolumn{8}{|c|}{ Taş yünü } \\
\hline & \multicolumn{4}{|c|}{ Yatay Delikli Tuğla } & \multicolumn{4}{|c|}{ Bims } \\
\hline Yakit tipi & $\begin{array}{l}\text { Optimum } \\
\text { yalıtım } \\
\text { kalınlığ } \\
\text { (m) }\end{array}$ & $\begin{array}{c}\text { Enerji } \\
\text { Tasarrufu } \\
\left(T L / m^{2}\right)\end{array}$ & $\begin{array}{c}\text { Ylllık } \\
\text { enerji } \\
\text { kazancl } \\
(\%)\end{array}$ & $\begin{array}{c}\text { Geri } \\
\text { ödeme } \\
\text { süresi } \\
(y ı l)\end{array}$ & $\begin{array}{l}\text { Optimum } \\
\text { yalıtım } \\
\text { kalınlığg } \\
\text { (m) }\end{array}$ & $\begin{array}{c}\text { Enerji } \\
\text { Tasarrufu } \\
\left(T L / m^{2}\right)\end{array}$ & $\begin{array}{c}\text { Yıllık } \\
\text { enerji } \\
\text { kazancı } \\
(\%)\end{array}$ & $\begin{array}{c}\text { Geri } \\
\text { ödeme } \\
\text { süresi } \\
(y u l)\end{array}$ \\
\hline
\end{tabular}
yıllık enerji kazanc1 


\begin{tabular}{|c|c|c|c|c|c|c|c|c|}
\hline Kömür & 0,057 & 101,505 & 52,506 & 1,905 & 0,046 & 45,393 & 34,896 & 2,896 \\
\hline Doğal Gaz & 0,068 & 148,179 & 57,869 & 1,728 & 0,058 & 71,543 & 41,523 & 2,408 \\
\hline
\end{tabular}

XPS için yapılan hesaplamalar sonucunda elde edilen değerler Tablo 4'te verilmiştir. XPS malzemenin 1sı iletim direnci daha yüksek oluğundan optimum yalıtım kanlığı değerleri hem kömür hem de doğalgaz için azalmıştır fakat XPS yalıtım levhalarının fiyatları diğer yalıtım malzemelerine göre yüksek olduğu için enerji tasarrufu ve yıllık enerji kazancı değerleri de azalmıştır. Bunun sonucunda geri ödeme süreleri de değişmiştir. Yatay delikli tuğla için bu değişim oldukça az olsa da bims kullanımında ise artış daha belirgindir. Bims kullanımında geri ödeme süresi kömür için 3,7 yıla doğalgaz için ise yaklaşık 3 yıla çıkmıştır.

Tablo 4. XPS için farklı yakıt türlerinde enerji tasarrufu, optimum yalıtım kalınlı̆̆ı, geri ödeme süresi ve yıllık enerji kazanci

\begin{tabular}{|c|c|c|c|c|c|c|c|c|}
\hline \multirow{2}{*}{$\begin{array}{c}\text { Yalıtım } \\
\text { malzemesi }\end{array}$} & \multicolumn{8}{|c|}{ XPS } \\
\hline & \multicolumn{4}{|c|}{ Yatay Delikli Tuğla } & \multicolumn{4}{|c|}{ Bims } \\
\hline Yakıt tipi & $\begin{array}{l}\text { Optimum } \\
\text { yalıtım } \\
\text { kalınlığ } \\
\text { (m) }\end{array}$ & $\begin{array}{c}\text { Enerji } \\
\text { Tasarrufu } \\
\left(T L / m^{2}\right)\end{array}$ & $\begin{array}{c}\text { Ylllık } \\
\text { enerji } \\
\text { kazancl } \\
(\%)\end{array}$ & $\begin{array}{c}\text { Geri } \\
\text { ödeme } \\
\text { süresi } \\
(y \mathrm{l} l)\end{array}$ & $\begin{array}{l}\text { Optimum } \\
\text { yalıtım } \\
\text { kalınlığ } \mathbf{l} \\
\text { (m) }\end{array}$ & $\begin{array}{c}\text { Enerji } \\
\text { Tasarrufu } \\
\left(T L / m^{2}\right)\end{array}$ & $\begin{array}{c}\text { Yıllık } \\
\text { enerji } \\
\text { kazancl } \\
(\%)\end{array}$ & $\begin{array}{c}\text { Geri } \\
\text { ödeme } \\
\text { süresi } \\
\text { (yll) }\end{array}$ \\
\hline Kömür & 0,036 & 87,908 & 45,473 & 2,199 & 0,027 & 34,636 & 26,626 & 3,756 \\
\hline Doğalgaz & 0,044 & 131,649 & 51,413 & 1,945 & 0,035 & 57,853 & 33,578 & 2,978 \\
\hline
\end{tabular}

EPS için yapılan hesaplamalar sonucunda elde edilen değerler Tablo 5'de verilmiştir. Ele alınan EPS ve XPS malzemelerinin 1sı özelliklerinin ve maliyetlerinin birbirine yakın olmaları sebebiyle elde edilen değerler de birbirine yakın çıkmıştır. Bu durum hem farklı yakıtlar için hem de farklı duvar bileşenleri için geçerlidir. EPS kullanımında maliyetin az da olsa düşük olması sebebi ile geri ödeme süreleri daha kısadır.

Tablo 5. EPS için farklı yakıt türlerinde enerji tasarrufu, optimum yalıtım kalınlığı, geri ödeme süresi ve yıllık enerji kazanc1

\begin{tabular}{|c|c|c|c|c|c|c|c|c|}
\hline \multirow{2}{*}{$\begin{array}{c}\text { Yalıtım } \\
\text { malzemesi }\end{array}$} & \multicolumn{8}{|c|}{ EPS } \\
\hline & \multicolumn{4}{|c|}{ Yatay Delikli Tuğla } & \multicolumn{4}{|c|}{ Bims } \\
\hline & $\begin{array}{l}\text { Optimum } \\
\text { yalıtım } \\
\text { kalınlığ } \\
\text { (m) }\end{array}$ & $\begin{array}{c}\text { Enerji } \\
\text { Tasarrufu } \\
\left(T L / m^{2}\right)\end{array}$ & $\begin{array}{c}\text { Ylllık } \\
\text { enerji } \\
\text { kazancl } \\
(\%)\end{array}$ & $\begin{array}{c}\text { Geri } \\
\text { ödeme } \\
\text { süresi } \\
\text { (yll) }\end{array}$ & $\begin{array}{l}\text { Optimum } \\
\text { yalıtım } \\
\text { kalınlığ } \\
\text { (m) }\end{array}$ & $\begin{array}{c}\text { Enerji } \\
\text { Tasarrufu } \\
\left(T L / m^{2}\right)\end{array}$ & $\begin{array}{c}\text { Ylllı } \\
\text { enerji } \\
\text { kazancl } \\
(\%)\end{array}$ & $\begin{array}{c}\text { Geri } \\
\text { ödeme } \\
\text { süresi } \\
\text { (yll) }\end{array}$ \\
\hline Kömür & 0,04 & 92,343 & 47,767 & 2,094 & 0,031 & 38,069 & 29,265 & 3,417 \\
\hline Doğalgaz & 0,048 & 137,063 & 53,528 & 1,868 & 0,04 & 62,266 & 36,139 & 2,767 \\
\hline
\end{tabular}

Tablo 6' da cam yünü için elde edilen değerler gösterilmiştir. Cam yünü için elde edilen değerler incelendiğinde en fazla optimum yalıtım kalınlığı değerinin bu malzemede elde edildiği görülmüştür. Yeterli bir yalıtım için daha fazla kalınlık gerektirse de geri ödeme süreleri göz önüne alındığında cam yünü levhaların en düşük geri ödeme süresine sahip olduğu görülmektedir. Bitlis pomzasından elde edilen bimsin duvar bileşeni olarak kullanılması durumunda ise diğer yalıtım elemanlarında olduğu gibi, düşük 1sı kaybından dolayı geri ödeme süresi artmıştır.

Tablo 6. Cam yünü için farklı yakıt türlerinde enerji tasarrufu, optimum yalıtım kalınlığı, geri ödeme süresi ve y1llik enerji kazancı 


\begin{tabular}{|c|c|c|c|c|c|c|c|c|}
\hline malzemesi & \multicolumn{4}{|c|}{ Yatay Delikli Tuğla } & \multicolumn{4}{|c|}{ Bims } \\
\hline Yakıt tipi & $\begin{array}{l}\text { Optimum } \\
\text { yalıtım } \\
\text { kalınlığg } \\
(\mathrm{m})\end{array}$ & $\begin{array}{c}\text { Enerji } \\
\text { Tasarrufu } \\
\left(T L / m^{2}\right)\end{array}$ & $\begin{array}{c}\text { Ylllık } \\
\text { enerji } \\
\text { kazancı } \\
(\%)\end{array}$ & $\begin{array}{c}\text { Geri } \\
\text { ödeme } \\
\text { süresi } \\
(y z l)\end{array}$ & $\begin{array}{l}\text { Optimum } \\
\text { yalıtım } \\
\text { kalınlığg } \\
(\mathrm{m})\end{array}$ & $\begin{array}{c}\text { Enerji } \\
\text { Tasarrufu } \\
\left(T L / m^{2}\right)\end{array}$ & $\begin{array}{c}\text { Yillık } \\
\text { enerji } \\
\text { kazancl } \\
(\%)\end{array}$ & $\begin{array}{c}\text { Geri } \\
\text { ödeme } \\
\text { süresi } \\
\text { (yll) }\end{array}$ \\
\hline Kömür & 0,077 & 111,766 & 57,814 & 1,730 & 0,065 & 53,924 & 41,454 & 2,412 \\
\hline Doğalgaz & 0,092 & 160,525 & 62,690 & 1,595 & 0,08 & 82,159 & 47,685 & 2,097 \\
\hline
\end{tabular}

\section{Sonuç ve Öneriler}

Bu çalışmada Bitlis ili için 2021 ekonomik verilerine göre, dış cephe yalıtımında gerekecek enerji tasarrufu, optimum yalıtım kalınlığı, geri ödeme süresi ve yıllık enerji kazancı değerleri hem kömür ve doğalgaz gibi farklı yakıtların kullanılması durumunda hem de bims (Bitlis Pomzası) ve yatay delikli tuğla gibi farklı yapı elemanlarının kullanılması durumunda hesaplanmıştır. Yakıt olarak kömür kullanıldığında optimum yalıtım kalınlığı doğalgaz kullanımına göre tüm durumlarda azalmıştır. En düşük optimum yalıtım kalınlığı 0,027 m olarak hesaplanmıştır ve bu değer yakıt olarak kömür, yalıtım malzemesi olarak XPS ve duvar bileşeni olarak bims kullanılması durumunda elde edilmiştir. En yüksek optimum yalıtım kalınlığı ise 1 sı iletim katsayısı en yüksek olan cam yünü malzemenin kullandığı yakıt olarak doğalgaz ve duvar bileşeni olarak ise yatay delikli tuğlanın kullanıldığı durumda hesaplanmıştır. Yine bu durumda en yüksek enerji tasarrufu ve yıllık enerji kazancı değerleri elde edilmiştir ve değerler sırasıyla $160,525 \mathrm{TL} / \mathrm{m}^{2}$ ve $\% 62,69$ 'dur. Bu senaryoda ödeme süresi de en düşük değerde hesaplanmıştır. En yüksek geri ödeme süresi ise malzeme olarak XPS, yakıt olarak kömür ve duvar bileşeni olarak bims kullanılması durumda 3,756 yıl olarak elde edilmiştir. Yalıtım kabiliyeti ve birim fiyat özellikleri geri ödeme süresinde etkili olmuştur. Yapı elemanı olarak bims kullanılması durumunda, yalıtım özellikleri duvar bileşeni tarafından da iyileştirilmiş olduğundan, geri ödeme süresi artmıştır. Bitlis ili pomza olarak zengin yeraltı kaynaklarına sahip olduğundan bölgede bims üretimi ve kullanımının artması, 1S1 kayıplarını azaltacak ve yalıtım maliyetini düşüreceğinden gerek bölgesel gerekse ulusal anlamda ekonomik bir katkı sağlayacaktır.

\section{Yazarların Katkısı}

Çalışmaya tüm yazarlar eşit oranda katkı sunmuştur.

\section{Çıkar Çatışması Beyanı}

Yazarlar arasında herhangi bir çıkar çatışması bulunmamaktadır.

\section{Araştırma ve Yayın Etiği Beyanı}

Yapılan çalışmada araştırma ve yayın etiğine uyulmuştur.

\section{Kaynaklar}

[1] United Nations Environment Programme Sustainable Buildings and Climate Initiative. Sustainable Buildings. 2021. https://www.unep.org/explore-topics/resource-efficiency/what-wedo/cities/sustainable-buildings, (Erişim Tarihi: 16.05.2021).

[2] Gölcü M., Dombaycı Ö. A., Abalı S. 2006. Denizli İçin Optimum Yalıtım Kalınlığının Enerji Tasarrufuna Etkisi ve Sonuçları. Gazi Üniversitesi Mühendislik Mimarlık Fakültesi Dergisi, 21 (4): 639-644. 
[3] Özel M. 2008. Bina Dış Duvarlarının Optimum Yalıtım Kalınlıkları İçin Dinamik Yaklaşım Ve Maliyet Analizi, Gazi Üniversitesi Mühendislik Mimarlık Fakültesi Dergisi, 23(4): 879-884.

[4] Kaynakli O. 2011. Parametric Investigation of Optimum Thermal Insulation Thickness for External Walls. Energies, 4(6): 913-927.

[5] Işık E., Tuğan V. 2017. Tunceli, Hakkâri ve Kars illerinin optimum 1sı yalıtım kalınlığının hesaplanması. International Journal of Pure and Applied Sciences, 3 (2): 50-57.

[6] Özel M., Tunç D. 2018. Kars ilindeki binalar için 1sıtma yükü ve optimum yalıtım kalınlığının belirlenmesi. Fırat Üniversitesi Mühendislik Bilimleri Dergisi, 30 (1): 251-257.

[7] Uçar A., Dumrul M.U. 2019. Bir konutun dış duvarları için 1sıtma ve soğutma yüklerine göre optimum yalıtım kalınlığın tespiti ve enerji tasarrufu analizi. Avrupa Bilim ve Teknoloji Dergisi, 16: 740-749.

[8] Bademlioglu A.H., Canbolat A S., Kaynakli Ö. 2018. Bina dış duvarlarında yoğuşma dikkate alınarak gerekli yalıtım kalınlığının belirlenmesi: Bitlis ili için örnek çalışma. Uludağ University Journal of The Faculty of Engineering, 23 (3): 333-340.

[9] Canbolat A.S., Bademlioglu A.H., Saka K., Kaynakli Ö. 2020. Investigation of parameters affecting the optimum thermal insulation thickness for buildings in hot and cold climates. Thermal Science, Part A, 24 (5): 2891-2903

[10] Canbolat A.S., Bademlioglu A.H., Kaynakli Ö. 2018. Determination of proper insulation thickness for building walls regarding economic consideration. International Research Journal of Advanced Engineering and Science, 3 (4): 173-176.

[11] Kürekçi N.A. 2016. Determination of optimum insulation thickness for building walls by using heating and cooling degree-day values of all Turkey's provincial centers. Energy and Buildings, 118: 197-213.

[12] Huang H., Zhou Y., Huang R., Wu H., Sun Y., Huang G., Xu T. 2020. Optimum insulation thicknesses and energy conservation of building thermal insulation materials in Chinese zone of humid subtropical climate. Sustainable Cities and Society, 52: 101840

[13] Kayan Y. 2019. Bitlis pomzas1 ile üretilen bimslerin mekanik özelliklerinin deneysel olarak araştırılması ve geliştirilmesi. Yüksek Lisans Tezi, Dicle Üniversitesi, Fen Bilimleri Enstitüsü, Diyarbakir. 1-66.

[14] Riggs J. 1. 1982. Engineering Economics. McGraw Hill, New York, 1-620. 